\title{
Lexico-Grammatical Principle of Verbal Lexemes Description (on the Material of the Russian Language)
}

\author{
Jamilia Nasykhovna Mustafina $^{1}$, Yevguenya Mikhailovna Maklakova ${ }^{1} \&$ Svetlana Olegovna Magfurova $^{2}$ \\ ${ }^{1}$ Naberezhnye Chelny branch (institute) of the Kazan Federal University, Tatarstan Republic, Naberezhnye \\ Chelny, Russian Federation \\ ${ }^{2}$ Naberezhnye Chelny branch of the University of Management (TISBI), Russian Federation \\ Correspondence: Svetlana Olegovna Magfurova, Naberezhnye Chelny branch of the University of Management \\ (TISBI), Russian Federation. Tel: 89-0-6118-5408. E-mail: maklakovaevgenya@mail.ru
}

Received: November 28, 2014 Accepted: December 26, 2014 Online Published: March 20, 2015

doi:10.5539/ass.v11n8p52

URL: http://dx.doi.org/10.5539/ass.v11n8p52

\begin{abstract}
This article discusses the functions of grammar in relation to lexical semantics and sets out to undertake lexico-grammatical analysis of some physiological verbs in the Russian language. It demonstrates the interaction of lexical and grammatical senses of a word in its structure on a specific language material. The verbs under discussion are: есть - yеst' (eat), пить - pit' (drink), лечить - lechit' (treat), беременеть - beremenet' (get pregnant), болеть - bolet' (be ill). This research is conducted by using descriptive-analytic method. It is worthwhile to find out to what extent verbal meanings can be presented through the system of grammatical categories. Lexico-grammatical characteristics of verbs with physiological meaning are presented within seven groups. Russian verbs have a number of categories which are not often taken into account in dictionaries. An attempt which brings together grammatical and semantic aspects of the verbs in a dictionary is made in this paper.
\end{abstract}

Keywords: vocabulary and grammar interaction, verbal units, Russian language, polysemy, lexicography, frame semantics

\section{Introduction}

Multidimensionality of developed linguistic theories and methods disclose an intricate description of the Russian language as a multifunctional system which various aspects are interrelated and interdependent. The vocabulary and grammar interaction in the system of language description is considered to be one of the core problems within modern linguistics. This problem has a long scientific tradition but it has not become less topical in modern linguistic research. Moreover the problem is exacerbated by the fact that many questions of vocabulary and grammar organization and content are not defined very clearly and consistently. Vocabulary and grammar as subsystems in the system of language dispose their elements which are significant and exist in certain relationships both between themselves and in their relations with reality. It is no accident that research on vocabulary and grammar interaction was preceded by works where lexical and grammatical systems are considered in isolation from each other. The validity of this approach is explained by the fact that the vocabulary and grammar have their own structural organization, contents and functional purpose. But in a word, lexical and grammatical meanings turned out to be so interrelated that the distinction between them is rather relative, of gnoseological nature, while in the ontological aspect a word is the unity of the lexical and grammatical meanings. According to V. V. Vinogradov, "in languages of such a system, as a Russian one, there are no lexical meanings which have not been grammatically formalized and classified. The notion of the formless words is not applied to the modern Russian language" (Vinogradov, 1972, p. 8).

\section{Method}

Thus, the description of grammar and semantics interaction on a particular linguistic material is possible, for example by implementing the lexical and grammatical principle of verbal units' description. Using system of verbal categories as a "filter" (in the terminology of V. G. Rudelev and A. L. Sharandin), we identify a semantic-grammatical characteristic in terms of the most abstract of lexical semantics, which should be a start of lexical units interpretation, specifying it when taken out from the text. 
This principle is also observed in relation to the polysemy: each lexical meaning or lexico-grammatical variant (LSV) is passed through the "filters" of grammatical categories and defined by its semantic and grammatical characteristic, which is an indicator of a lexico-grammatical class (grade) (Rudelev \& Sharandin, 1981, pp. 32-54).

\section{Results}

\subsection{Lexico-grammatical Characteristics of Verbs with Physiological Meaning}

As a result, investigated verbs with physiological meaning were represented in various lexico-grammatical classes (grades) of a verb. On the basis of traditionally distinguished grammatical categories (of mood, tense, type, voice, person, noun) their representation is found in the classes with the following lexico-grammatical characteristics.

The first class includes lexical units that implement in full the paradigm of verbal categories of mood, tense, aspect, voice, person (gender) and a number. They express the abstract lexical semantics of active limit physiological human actions aimed directly at the object. With regard to the relationship of abstract and specific lexical semantics this class includes, for example, the verb yest' (lit. to eat) meaning "to receive, to absorb food" (about a person) in the defining dictionaries. In our interpretation it is: "active limit physiological human action, aiming directly at the object with the purpose of reception and absorption of food". Compare also pit' (lit. to drink): "active limit physiological human action, aiming directly at the object with the purpose of satisfaction of needs in a liquid"; lechit' (lit. to treat): "active limit human action, aimed directly at the object under a certain influence with the aim of cure".

The second class entails lexical units denoting the physiological limit sign, directed to the object with a specific purpose. Unlike lexical units in first class the subject is an animal due to which the sign of "action" is defined by us as a physiological process. Grammatically lexical units are characterized by defect structure of mode and person paradigms. The interpretation of, for example, the verb yest' (lit. to eat) in relation to a subject-animal is represented as "active limit physiological process of instinctive nature, inherent in animals and aimed directly at the object with the purpose of reception and absorption of food". As you can see, the differences between the lexical units of the first and second classes are found at the level of abstract lexical semantics, rather than at the level of established specific (dictionary) meanings. This class is presented by specific meanings: yest' (lit. to eat) - "damage, destroy, eat biting (about rodents, insects)" or "active limit physiological process carried out by rodents, insects, and aimed directly at the object subjected to damage or destroys". This class covers also verbs denoting a feature plants inherent, because traditionally allocated to the categories of person they are characterized by the absence of first and second persons forms. For example, pit' (lit. to drink) in the meaning "absorb moisture from the soil (about a plant)".

The third class covers, for example, a lexical unit beremenet' (lit. become pregnant) (about a woman). Taking into account the abstract of lexical semantics this lexical unit indicates the "limit physiological action of woman with the purpose of procreation (the birth of babies)", which was reflected in the grammar of the lexical unit, in particular, in defects of the voice paradigm.

Unlike the lexical unit beremenet' (lit. become pregnant), the meaning byt' beremenoy (lit. be pregnant) marked in dictionaries, has a different lexico-grammatical characteristics: "non-limiting physiological condition woman inherent when she is in the condition of pregnancy".

The verb beremenet' (lit. become pregnant) is used in relation to a animal subject presented, naturally, by a female. In this case, we give the following interpretation: "instinctive physiological process, allowing animal females to ensure the existence and development of the respective species of animals". Along with defective structure of voice paradigm, here defects of the mode and person categories are detected. As for the category of gender, in relation to the meanings of the verb (to become pregnant), it is characterized by the absence of male forms.

The fourth class consists of lexical units with an abstract lexical semantics transmitting the meaning of non-limiting procedure characteristic inherent in the inanimate entities and aimed at the object. In grammatical terms these lexical units detect defects of the paradigms of mood, aspect and person. Thus the verb "yest"' (lit. to eat) meaning "annoy, corrode (about smoke)" is described as "non-limiting procedure characteristic inherent in an inanimate subject (smoke, dust and others) and directed to the object (body parts) with the result that an object receives an irritation".

The fifth class comprises lexical units denoting "non-limiting human physiology". For example, the verb bolet' (lit. to be ill) meaning "suffer any disease", i.e. we have the combined meaning - "non-limiting physiological 
state of a person, being ill with any disease). In grammatical terms this meaning determines the defects of the mood, aspect and voice paradigms. If the subject is not a person but an animal, this is reflected in the defects of the person category, which allows to distinguish the sixth lexico-grammatical class, represented, for example, by the specific meaning of the verb bolet' (lit. to be ill) - "suffer from pain (on any part of the body)": "non-limiting state, manifested by pain sensation experienced by a person or an animal in any part of the body".

Functioning of the verbs in the judgment of type "all living creatures eat and drink" enables eliminating the seventh class, which includes lexical units with an abstract lexical semantics transmitting the meaning of a constant physiological characteristic, providing an instinctive need in the food and liquid for living creatures. In grammatical terms, verbal units that realize their meaning in the context of statements like judgments are presented only by original forms of mood, tense and aspect categories.

Involvement of grammatical material on aspectuality, causative nature, reflexivity and the real gender allowed seeing their possibilities in the lexico-grammatical groups' description. As presented in the second class of the verbal units, denoting a feature inherent to the animal-subject and plant-subject based on the category of the real gender, can be considered as representatives of different classes. When a feature is inherent in the animal, it has a physiological nature, whereas with the plant-subject it is preferable to classify it as of biological nature.

Allocated lexico-grammatical classes of verbs with the meaning of physiological characteristic detect different semantic and grammatical "force" in the general system of a verb as a part of speech. Thus, the most "forceful", the most "powerful" lexico-grammatical class should be recognized the class of verbs denoting "active limit physiological human actions, aiming directly at the object" and the less "significant" class is the one of the verbs denoting "permanent physiological trait, characteristic of living beings". Semantic (significance) of the first class is confirmed by the richness and fullness of the implemented paradigms of all grammatical categories inherent to the verb as a part of speech, the ones of mood, tense, aspect, voice, person (gender) and number.

\subsection{Lexicographical Aspect of "Physiological" Verbs' Description (on the Material of the Russian Language)}

Due to the diversity of meanings and connotations of a word one way or another connected with their formal (grammatical) utterance, the relationship of polysemy and grammar continues to be relevant. Thus, the analysis of the meanings of the Russian verb (eat) demonstrates this relationship through its different meanings having different grammatical characteristics. Cf.: the meaning "receive, absorb food (about a person)" implements a complete paradigms of mood, tense, aspect, voice, person, number. Whereas the meaning "damage, destroy, eat biting (about rodents, insects)" does not implement in full the category of mood, person; and the meaning "annoy, corrode (about smoke)" loses its form of perfective aspect. Such examples reinforce the point that verbs have two distinctive meanings: one of them is the "root", the second one - "event structure template" (Kemmerer, 2010, pp. 54-76).

\section{Discussion}

The described multivalent verbs with the physiological characteristic meaning permitted to see certain semantic shifts that caused changes in the grammatical functioning of the lexical units. The greatest semantic difference is connected with the change of subject qualification, when it is not a person but an inanimate object (cf.: smoke eats eyes; rust eats iron). The concept of physiological characteristic in this case, in our opinion, is rather relative, because objects (often parts of the body) suffer negative effects most likely of physical nature (irritation and destruction). In grammatical terms this semantic shift is the most noticeable: imperative forms, the ones of the first and second person are not used. Therefore it's no coincidence that this semantic shift is most often noted by lexicographers. As for the subject opposition of (human-animal), the differences in the nature of the subject is not always considered as different LSV, because often these differences don't occur at the level of individual lexical meaning, but at the level of abstract lexical semantics. So, for a person, in particular a meal (physiological characteristic) is shown as "physiological action", which has both natural (instinctive) nature and conscious activity act. For animals the same meal is likely a physiological process of instinctive nature, which is reflected in the category of mood - the missing paradigm in the imperative (Magfurova, 2004, pp. 90-96).

The question about the place and function of grammar has two fundamentally different views among specialists in Russian lexicography. So, L. V. Shcherba expressed the opinion about the excessive expansion grammatical apparatus in dictionaries, while V. V. Vinogradov noted the insufficient grammar penetration in a dictionary (Shcherba, 1974; Vinogradov, 1969).

Naturally, this dispute needs an (aurea mediocritas), as the formal transfer of grammatical descriptions in the lexicographic practices does not solve the problem of vocabulary and grammar interaction. Therefore, the majority of linguists tend to accept the existence of a dictionary grammar, which would take into account both 
the achievements of modern grammatical theory and specifics of its lexicographic sort. We agree that "we need a theory that links the meanings of words very explicitly to the syntactic contexts in which those words are used, and to the semantic properties of those contexts" (Cowie, 2006, p. 133). Considerable interest is currently being shown by researchers in lexicology and, particularly, in lexicography in "frame semantics theory", which enables lexicographers to see how all categories of the verbs are captures in one entry (Fillmore, 2006, pp. 613-620). The practical applicability of this theory is acknowledged in some other works (Aslani, 2013, pp. 99-114; Cowie, 2006, p. 133; Zainudin, 2014, pp. 2316-2320).

In particular, if we proceed from the premise that the word represents a unity of lexical and grammatical values, it is necessary to understand the mechanism of inclusion grammatical material in the interpretation of the dictionary meaning of the word. An attempt to give meaning to this mechanism is found in the article of A.L. Sharandin "To the problem of grammatical concepts in an explanatory dictionary" (Sharandin, 1998, pp. 235-241). Adopting basic provisions of this article, we attempted to reveal some LSV of analyzed multivalent verbs taking into account both specific lexical semantics and abstract lexical semantics of an LSV given in a dictionary entry. As a result, for example, a dictionary entry of the verb "eat" bears the following aspect (taking into account the traditionally distinguished meanings and grammatical categories). Here is a lexicographical representation of the Russian verb yest' (in English eat) and its different forms and meanings:

1) Yest'(lit. to eat) - imper. yesh (lit. you eat); perf. syest' (lit. to eat up, i.e. to finish eating); pass. yestsya, syeden etc. (i.e., be being eaten, to be eaten); causative verb kormit' (lit. to feed); refl. yestsya (i.e. be being eaten, it is eaten).

Active limit physiological human action, aiming directly at the object with the purpose of food reception and absorption (eat some porridge, bread etc.).

2) Yest' (lit. to eat) - 3 person pl. yedyat (lit. they eat); perf. syest' (lit. to eat up, i.e. to finish eating); pass. yestsya, syeden (i.e. to be eaten, it is eaten); refl. yestsya (i.e. to be eaten).

Active limit physiological process carried out by rodents and insects, aimed directly at the object, and perceived by a human as spoilage, destruction of the object (eat/bite the floor, wallpapers etc.; bite/sting people).

3) Yest' (lit. to eat) - 3 person pl. yedyat (lit. they eat); imperf. yest' (lit. to eat); pass. yestsya, syeden (i.e. to be eaten, it is eaten).

Fig. expression:

Non-limit process (stative) feature inherent in some subjects (smoke, dust etc), the effects of which leads to physical irritation (smoke eats eyes).

4) Yest' (lit. to eat) - 3 person pl. yedyat (lit. they eat); imperf. yest' (lit. to eat); pass. yestsya, syeden (i.e. to be eaten, it is eaten).

Fig.expression:

Non-limit physical process resident in certain subjects (rust, acids etc), the effects of which causes their chemical destruction (rust eats iron).

The analyzed material showed some different distinctive capabilities of the abstract and specific lexical semantics of the word in its structure. There are three common cases:

1) LSV may differ both at the level of a specific lexical semantics, and at the level of abstract lexical one. Comp. yest' (lit. to eat) in the meaning "to receive, to absorb food) and in the sense "to annoy, corrode (about smoke)", which at the level of abstract lexical semantics implements seme "action" (eat food: bread, cereal etc.) and "no-action" (smoke eats eyes). It is confirmed by the fact that the second meaning of "eat" is not able to realize both the imperative form and the form of first and second persons.

2) LSV cannot differ at the level of abstract lexical semantics, but they differ at the level of a specific lexical semantics, i.e. the functional yield in meanings delimitation is born by specific lexical semantics. Comp., for example, the distinction between the meanings of the lexeme "pit" (lit. drink) 1) swallowing absorb any liquid and 2) drink alcoholic beverages, which at the level of basic grammatical categories functioning implement the same model expressing an abstract lexical semantics of a limit human action, which is directed at the object with the purpose of satisfying physiological needs in a liquid.

3) LSV may not differ at the level of a specific lexical semantics, but they discover the difference at the level of abstract lexical semantics. Thus, the meaning of the verb "lechit"" (lit. treat) in (to restore health, to recover by a treatment) in respect of a human subject (doctor treats...) is included in scope of "action", and in respect of 
non-human subject (horse treats...) - in the sphere of "no-action" (a biological life). As the specific material shows, differences in the abstract lexical semantics with the common specific lexical semantics are not always recorded in dictionaries or are not marked logically enough.

In the end, we emphasize the fact that one of the important moments in the description of lexico-grammatical models, fixing abstract lexical semantic and grammatical categories relationship, represented by a composition of their paradigms is that these models are not equal in the lexical system of the language. They differ by their semantic and grammatical (force) that let open up certain hierarchical relations between them and see models cooperation between each other. So, the most powerful, (solid) lexico-grammatical class of verbal units meaning physiological characteristic in relation to nuclear, verbal categories proper is the class of action verbs, but the (lightest) is the class of lexemes denoting a permanent physiological feature.

\section{Conclusion}

These results may be of great importance, taking into account the necessity of studying the Russian language, its grammar (Sadıkoğlu \& Bicen, 2014, pp. 5046-5052). As it was pointed, grammar is becoming a prominent feature in dictionaries (Ellendersen, 2007, p. 82). And not only in dictionaries, but in real-time talk (Fox, 2007). The lexico-grammatical analysis of particular verbs of the physiological characteristic and the consideration of lexical semantics in terms of interaction with grammar allowed, to some extent, to identify a deep linguistic entity of such word classes, as lexico-semantic groups.

Linguists tend to use morphological characteristics when considering lexicological problems as "the lexical system of a language is not just a set of lexico-semantic groups, but firstly the system of parts of speech, within which there is a variety of lexico-semantic groups" (Kuznetsova, 1989, p. 84). In addition, "lexico-semantic groups, as an element of one or another part of speech (aparticular lexico-grammatical class of words), must also be in terms of the interaction of lexical semantics and grammar. Due to the formal expressiveness semantic differences become definite that allows us to distinguish between words with the same or a different meaning from the other words." (Sharandin, 1995, p. 5). Lexico-semantic classification becomes a continuation of the lexico-grammatical classification at that stage, when the distinctive features of grammar in relation to the language have been exhausted (Magfurova, 2004, pp. 90-96).

The card index of verbs of the physiological characteristic (1868 units) compiled from the corpus of defining dictionaries of the Russian language shows some inconsistencies and contradictions of presenting polysemantic verb lexemes. A different view of dictionary representation of verb lexemes is offered in this paper from the perspective of lexical morphology, namely: the meanings of lexemes are given in a certain sequence as a system of decreasing semes, which corresponds to a reduction in the number of grammatical forms and the relevant categories. Furthermore, we believe that the verbal lexeme must be submitted not in alphabetical order but in order of representations of a lexico-grammatical class.

As shown by the specific material, this dictionary view of polysemantic verbal lexemes takes into account not only the distinction between characters, but their interaction, resulting in mixing, neutralization under certain conditions. Neutralization, or a mixture of linguistic symbols in a weak position, functionally justified and driven by the desire to increase the communication speed. Currently linguistic literature on neutralization at different levels of functioning of language is quite extensive, and the development of this problem is considered to be a promising direction in the study of the morphological system of the language (Bulygina, 1969; Rudelev, 1972; Shelyakin, 1977; Vinogradov, 1972, p. 18). In our opinion, the use of the theory of neutralization in lexicographic practice will consistently comply with the postulate of the linguistic sign, according to which a linguistic sign language should not be multivalent.

Observations of unequal paradigms, organized by verbal categories and by the differences in the lexical semantics of a multivalent linguistic unit, allow us to set the following pattern: the complete paradigm shows not only the formal richness of a particular lexeme, but also the richness of its lexical semantics, which is depicted in such an objective process of neutralization.

Thus, the lexico-grammatical analysis of verbs of the physiological characteristic showed that the identification and description of the lexical semantics of the verb lexemes on the basis of the functioning of grammatical categories will continue to create a dictionary of a new type, namely lexical and grammatical dictionary of the Russian language, which would contain information about the capabilities of functioning in the speech of one or another linguistic verbal sign and situation that it describes. As a result, we have the opportunity to receive objective information not only about the original system of lexical values, but also about the conditions of use of linguistic symbols. 


\section{References}

Aslani, M. R. (2013). Frame Semantics, Metalexicography and the Microstructure of Persian Monolingual Dictionaries. International Journal of Linguistics, 5(3), 99-114. http://dx.doi.org/10.5296/ijl.v5i3.3520

Bulygina, T. V. (1969). About the neutralization of semantic oppositions. Units of different levels of grammatical structure of the language and their interaction. Moscow.

Cowie, A. (2006). Lexicology (p. 133). University of Leeds, Leeds, UK. Elsevier Ltd.

Ellendersen, J. (2007). Grammar in dictionaries of languages for special purposes. Cand. ling. merc (tt) thesis. Aurhus School of Business, 82. Retrieved from http://pure.au.dk/portal/files/1462/000161028-161028.pdf

Fillmore, C. J. (2006). Frame Semantics. Encyclopedia of Language \& Linguistics (2nd ed., pp. 613-620). http://dx.doi.org/10.1016/B0-08-044854-2/00424-7

Fox, B. A. (2007). Principles shaping grammatical practices: An exploration. Discourse Studies. Retrieved from http://dis.sagepub.com/content/9/3/299

Kemmerer, D. (2010). The Two-Level Theory of verb meaning: An approach to integrating the semantics of action with the mirror neuron system Brain and Language. Mirror Neurons: Prospects and Problems for the Neurobiology of Language, 112(1), 54-76.

Knyazev, Y. P. (1979). Neutralization of morphological oppositions in a series of related phenomena grammar (in Russian language). Category of certainty-uncertainty in Slavic and Balkan languages. Moscow.

Kuznetsova, E. C. (1989). Lexicology of the Russian language (p. 84). Moscow.

Magfurova, S. O. (2004). Verbs with the value of the physiological characteristic in the lexico-grammatical and lexico-semantic aspects. Cultural Ecology: The life of language (pp. 90-96). Arkhangelsk: Publishing house of the Pomor State University.

Rudelev, V. G. (1972). Types of neutralization and classification of oppositions. Problems of structural linguistics. Moscow.

Rudelev, V. G., \& Sharandin, A. L. (1981). Encrypting the role of the verbal grammatical categories. Theory of the substantial form, 32-54. Tambov.

Sadıkoğlu, S., \& Bicen, H. (2014). Evaluation of University Student's Opinions about Learning Russian Language. Procedia-Social and Behavioral Sciences. 5th World Conference on Educational Sciences, 116, 5046-5052. http://dx.doi.org/10.1016/j.sbspro.2014.01.1071

Sharandin, A. L. (1995). Polysemy and morphology of the Russian verb (p. 5). Tambov.

Sharandin, A. L. (1998). To the issue of a grammatical concept explanatory dictionaries. Russian Philology: Linguistic paradigm of the end of the 20th century (pp. 235-241). St. Petersburg, St. Petersburg state University.

Shcherba, L. V. (1974). Experience of the General theory of lexicography. Linguistic system and speech activity. Leningrad, Nauka.

Shelyakin, M. A. (1977). To the question of the methodological foundations of the system-structural description of grammatical categories. Uchenye Zapiski (Vol. 425). Works on Russian and Slavic Philology, 29. A series of linguistic/the University of Tartu.

Vinogradov, V. V. (1969). About the interaction of lexico-semantic levels with the grammatical structure of the language. Thoughts about the contemporary Russian language (pp. 15-21). Moscow, Prosveshchenie.

Vinogradov, V. V. (1972). English language (Grammar teaching on the word) (p. 18). Moscow, Visshaya Shckola.

Zainudin, I. S. (2014). The Use of Corpus and Frame Semantics in a Lexicography Class: Evaluating Dictionary Entries Procedia-Social and Behavioral Sciences. 5th World Conference on Educational Sciences, 116, 2316-2320.

\section{Copyrights}

Copyright for this article is retained by the author(s), with first publication rights granted to the journal.

This is an open-access article distributed under the terms and conditions of the Creative Commons Attribution license (http://creativecommons.org/licenses/by/3.0/). 